\title{
INFLUÊNCIA DA KLABIN NO MERCADO DE MADEIRA EM TORA DO ESTADO DO PARANÁ
}

\author{
Alexandre Nascimento de Almeida ${ }^{1}$, João Carlos Garzel Leodoro da Silva² ${ }^{2}$ Humberto Angelo ${ }^{3}$
}

(recebido: 3 de maio de 2010; aceito: 25 de novembro de 2011)

RESUMO: A Klabin é a maior empresa de base florestal do Estado do Paraná. A ela pertence não somente a maior parte dos reflorestamentos do Estado, como também a responsabilidade pela maior oferta de madeira para o processamento mecânico e o maior consumo de madeira fina do Paraná. Essas características conferem à empresa grande poder de mercado e capacidade de influenciar na formação do preço da madeira. Este trabalho aborda a influência da Klabin na formação do preço da madeira no Paraná. Como base metodológica, empregou-se o teste $t$ de Student para comparar o preço da madeira para celulose e o processamento mecânico dentro e fora da região de atuação da Klabin no ano de 2008. Os resultados não indicaram uma diferença entre os preços nas regiões analisadas que pudesse ser justificada pelo poder de oligopólio e oligopsônio da empresa, ou seja, a empresa possui poder de mercado, mas não o utiliza.

Palavras-chave: Estrutura de mercado, economia florestal, planejamento estratégico, preço da madeira.

\section{KLABIN'S INFLUENCE IN ROUDWOOD MARKET OF PARANA STATE}

\begin{abstract}
Klabin is the largest forest company of Parana. The company owns most of the Parana's reforestation, provide the majority of sawnwood supply and it is responsible by highest consumption of Parana's pulpwood. These characteristics give the company a considerable market power and an ability to influence the formation of timber price. The objective was to contribute to the understanding of the Klabin's influence on the formation of timber prices in Parana. By using Student test the price of pulpwood and sawnwood within and outside of Klabin's operation area in 2008 was compared. The results indicated no difference among prices in regions that could be considered justified by the power of oligopoly and oligopsony from the company; in other words, the company has market power, but does not use it.
\end{abstract}

Key words: Market structure, forest economics, strategic planning, wood price.

\section{INTRODUÇÃO}

O Paraná é um Estado de grande importância no mercado de madeira de silvicultura, é o terceiro maior produtor de madeira para lenha e para celulose e papel, tendo respondido, em 2008 , por $15 \%$ da produção nacional desses produtos. Em relação à produção de madeira para o processamento mecânico, o Estado lidera com folga: em 2008 , respondendo por $32 \%$ da produção nacional, produzindo $60 \%$ mais madeira de silvicultura para esse fim que São Paulo, segundo colocado (INSTITUTO BRASILEIRO DE GEOGRAFIA E ESTATÍSTICA IBGE, 2010).

Levando-se em conta que o comércio de madeira em tora é mais ativo para a indústria do processamento mecânico, já que as grandes empresas de celulose e siderúrgicas são menos dependentes de madeira do mercado, o Paraná acaba se tornando uma referência para estudos que busquem entender o comércio desse produto.
Em 2007, o Estado possuía aproximadamente 3 mil empresas de base florestal; destas, $48 \%$ eram ligadas à fabricação de produtos de madeira, $11 \%$ à fabricação de celulose, papel e produtos de papel e $41 \%$ à produção de artigos do mobiliário (IBGE, 2010). Entre as empresas de base florestal, a de maior importância no Estado é a Klabin, possuindo a maior área de reflorestamentos próprios; em 2005, respondeu por cerca de $24 \%$ dos plantios de Pinus e Eucalipto do Paraná (ALMEIDA, 2006).

O tamanho da Klabin, tanto em área plantada como na área industrial, torna-a a maior fornecedora brasileira de toras para o processamento mecânico e a maior consumidora de madeira para celulose no Paraná. Naturalmente, a grande participação da empresa tanto na oferta quanto no consumo de madeira em tora proporcionalhe um considerável poder de mercado, somando-se ao fato de que a maioria de seus parceiros comerciais é de pequenos produtores que vendem madeira fina e um grande número de madeireiras que compram a madeira

\footnotetext{
${ }^{1}$ Engenheiro Florestal, Professor Doutor em Engenharia Florestal - Faculdade UnB de Planaltina/FUP - Universidade de Brasília/UnB - Área Universitária n. 1 - Vila Nossa Senhora de Fátima - Planaltina, DF - 73300-000 - alexalmeida@unb.br

${ }^{2}$ Engenheiro Florestal, Professor Doutor em Economia Aplicada - Departamento de Economia Rural e Extensão - Universidade Federal do Paraná/UFPR Av. Lothário Meissner, 900 - Jardim Botânico - Campus III - 80210-170 - Curitiba, PR - garzel@ufpr.br

${ }^{3}$ Engenheiro Florestal, Professor Doutor em Economia e Política Florestal - Departamento de Engenharia Florestal - Faculdade de Tecnologia Universidade de Brasília/UnB - Asa Norte - Cx. P. 04357 - 70919-970 - Brasília, DF - humb@unb.br
}

Cerne, Lavras, v. 18, n. 1, p. 153-158, jan./mar. 2012 
um pouco mais grossa; portanto, seu poder de mercado é inverso ao da Klabin.

Outro fator que coloca a empresa em uma excelente posição de barganha na compra de madeira é o fato de ela não ser dependente exclusivamente do mercado para o seu suprimento de madeira - justamente por deter uma grande base florestal própria e produzir madeira em tora suficiente para atender à maior parte de suas necessidades.

Outra vantagem que essa empresa possui - comum às empresas de papel e celulose - é que ela conta com uma considerável mobilidade no aproveitamento da madeira em diferentes diâmetros, proporcionando certa liberdade em direcionar sua produção para os diferentes fins, conforme suas necessidades. Segundo Graça et al. (2000), é comum grandes empresas comprarem glebas de reflorestamento, nas mais diferentes idades e densidades, ou madeira de terceiros a um custo mais baixo que o seu. Com isso, elas podem estrategicamente usar sua madeira própria para fins mais valiosos ou para suprir futuramente demandas que lhes sejam mais oportunas.

Conforme Souza (2005), um fator que prevaleceu durante muito tempo em grandes empresas de base florestal é a prática adotada de "corte raso", para as madeiras compradas de fornecedores, e de "corte seletivo", para aquelas retiradas de seus próprios cultivos.

Considerando que o mercado florestal é bastante regionalizado em virtude do alto custo de transporte da madeira em toras, os poderes referentes ao oligopólio e oligopsônio das grandes empresas florestais no comércio de madeira podem ser ampliados, dependendo da acessibilidade e localização da floresta. Assim, os altos custos inerentes ao transporte da madeira em tora podem limitar o número de possíveis compradores de madeira ou inviabilizar a exploração de outras fontes alternativas de florestas (ALMEIDA, 2006).

Em geral, os trabalhos que abordaram o tema "estrutura de mercado" no setor florestal utilizaram índices de concentração e buscaram caracterizar uma estrutura de mercado em questão (LEITE; SANTANA, 1998; NOCE et al., 2007; SANTOS; SANTANA, 2003; SOARES et al., 2006). Entretanto, o mais importante para a sociedade não é saber se uma estrutura é concentrada ou não, e sim identificar se uma empresa, ou grupo de empresas, influencia ou não o preço de um bem. Naturalmente, uma concentração de mercado por si só não garante um controle sobre os preços nem que o mercado opera de forma ineficiente; esse controle depende da estratégia e do tipo de relacionamento entre as empresas (PINDICK, 1999).

Conforme Leite e Santana (1998), a existência de alta concentração em um mercado não implica necessariamente a existência de práticas oligopolistas, dado que as empresas líderes, além da obtenção de economias de escala, podem ser levadas a buscar inovações tecnológicas e se modernizar.

Este trabalho trata da influência da maior empresa de base florestal do Estado do Paraná, na formação do preço da madeira em sua área de atuação. Especificamente, buscou-se verificar se o preço médio da madeira para celulose e processamento mecânico na área de atuação da Klabin apresenta diferença estatisticamente significativa daquele praticado no restante do Estado.

\section{MATERIAL E MÉTODOS}

\subsection{Referencial teórico}

Conforme a teoria econômica é esperada que uma empresa em uma estrutura de oligopólio regule sua produção de forma que consiga cobrar um preço superior ao daquela em concorrência perfeita e inferior àquele cobrado em um monopólio. Já, o oligopsonista pode influenciar os preços de determinado bem, variando a quantidade comprada e, similar ao oligopólio, seu poder de influência encontra-se em uma situação intermediária à do monopsônio e à do mercado plenamente competitivo (PINDICK, 1999).

Dessa forma, assumiu-se que, dentro da área de atuação da Klabin, ocorre uma maior concentração no mercado de madeira comparativamente ao Estado do Paraná como um todo e, espera-se, que o preço da madeira seja determinado conforme os interesses da empresa, ou seja, que o preço médio da madeira praticado nessa região seja inferior para celulose e superior para o processamento mecânico, quando comparado ao do restante do Estado.

Souza (2005), em um estudo que também considerou a área de atuação da Klabin, apontou que a grande maioria das empresas ligadas ao desdobramento e laminação na região está totalmente dependente de fornecimento de madeira por parte das grandes indústrias "papeleiras", que detêm os plantios de florestas ou a preferência de compra junto aos produtores rurais. Segundo esse autor, essas indústrias, chamadas de "fornecedoras de toras", abastecem as madeireiras num raio que varia até um limite de $75 \mathrm{~km}$ - distância a partir da qual se torna antieconômica a busca e o fornecimento de madeira.

Cerne, Lavras, v. 18, n. 1, p. 153-158, jan./mar. 2012 
A partir das considerações de Souza (2005), definiram-se, como área de atuação da Klabin, todos os municípios dentro de um raio próximo de $75 \mathrm{~km}$ de Telêmaco Borba, município sede da empresa (Figura 1).

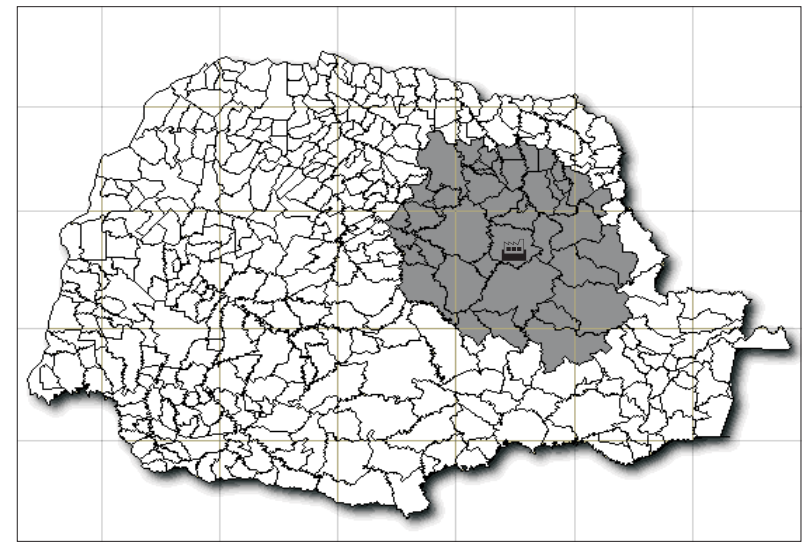

Figura 1 - Área assumida de atuação da Klabin.

Figure 1 - Assumed area of Klabin's operation.

\subsection{Referencial analítico}

O teste comparativo de médias foi o teste paramétrico $t$ de Student para amostras independentes e de tamanhos diferentes. Em virtude da disponibilidade de dados, a amostra dentro da região de atuação da Klabin contabilizou informações para 26 e 40 municípios para o preço de madeira para celulose e processamento mecânico, respectivamente. Já, fora da região, encontrou-se um maior conjunto de dados para celulose e processamento mecânico, totalizando 57 e 309 municípios amostrados, respectivamente.

As hipóteses assumidas foram:

$\mathrm{H}_{0}: \mu$ dentro da região de atuação da Klabin $=\mu$ fora da região de atuação

$\mathrm{H}_{1}: \mu$ dentro da região de atuação da Klabin $\neq \mu$ fora da região de atuação

em que: $\mu$ é o preço médio da madeira para celulose e processamento mecânico.

De acordo com Pestana e Cageiro (2005), quando as amostras têm dimensão inferior ou igual a 30, os testes $t$ exigem que os grupos em análise tenham distribuição normal. Dessa forma, foi analisada apenas a normalidade da amostra referente ao preço para celulose dentro da região de atuação (26 casos). Para isso, aplicou-se o teste de normalidade de Shapiro-Wilk. Em caso de violação da normalidade, como alternativa ao teste $t$, foi aplicado o teste não paramétrico de Mann-Whitney.
Antes de optar pelo teste $t$, que assume e não assume igualdade de variância dentro das diferentes amostras, aplicou-se o teste de Levene para a fundamentação dessa escolha.

Para todos os testes aplicados (Shapiro-Wilk, Levene e teste $t$ ), admitiu-se um nível de significância de $5 \%$, nível este, normalmente aceito em pesquisas na área de ciências econômicas.

\subsection{Banco de dados}

Os dados utilizados foram coletados junto ao IBGE (2010) por meio de sua pesquisa para silvicultura para o ano de 2008. Encontram-se disponíveis dados para 84 e 350 municípios, conforme os respectivos preços da madeira para celulose e processamento mecânico. Os valores unitários para os preços foram obtidos pela razão entre o valor da produção e a quantidade produzida.

\section{RESULTADOS}

\subsection{Análise da normalidade}

O teste de Shapiro-Wilk rejeitou a ausência de normalidade para o preço da madeira para celulose dentro da área de atuação da Klabin em nível de significância de $5 \%$, atestando, assim, a aplicação do teste paramétrico $t$ (Tabela 1).

Tabela 1 - Resultados do teste de normalidade de Shapiro-Wilk para o preço da madeira para celulose dentro da região de atuação da Klabin (PCRA).

Table 1 - Results of Shapiro-Wilk's normality test for the price of pulpwood in the region of Klabin's operation (PCRA).

\begin{tabular}{cccc}
\hline & Estatística & gl & Sig. \\
\hline PCRA & 0,93 & 26 & 0,08 \\
\hline
\end{tabular}

\subsection{Análise da variância}

O teste de Levene indicou uma igualdade de variância dentro das amostras, apontando para a aplicação do teste $t$ que assumisse essa característica. O nível de significância do teste aplicado foi de 0,28 para a comparação do preço para celulose (PC) dentro e fora da área de atuação da Klabin e de 0,45 para a comparação do preço para o processamento mecânico (PPM). Esses resultados levam à rejeição da hipótese da não igualdade de variâncias e mostram que não existe maior dispersão dos preços da madeira dentro ou fora da área de atuação da Klabin (Tabela 2).

Cerne, Lavras, v. 18, n. 1, p. 153-158, jan./mar. 2012 
Tabela 2 - Resultados do teste de Levene para os comparativos entre os preços da madeira para celulose e processamento mecânico dentro e fora da área de atuação da Klabin.

Tabela 2 - Results of Levene's test for comparing the price for pulpwood and sawnwood within and outside of Klabin's operation area.

\begin{tabular}{lccc}
\hline & & $\mathrm{F}$ & Sig. \\
\hline \multirow{2}{*}{ Igualdade de variâncias assumidas } & $\mathrm{PC}$ & 1,19 & 0,28 \\
\cline { 2 - 4 } & $\mathrm{PPM}$ & 0,59 & 0,44 \\
\hline
\end{tabular}

Portanto, a fórmula aplicada do teste $t$ foi conforme a equação (1), considerando tamanho de amostras diferentes e variâncias iguais dentro da amostra.

$\mathrm{t}=\frac{\mathrm{x}_{1}-\mathrm{x}_{2}}{\mathrm{~S}_{\mathrm{x} 1 \times 2} \cdot \sqrt{\frac{1}{\mathrm{n}_{1}}+\frac{1}{\mathrm{n}_{2}}}}$

onde:

$\mathrm{S}_{\mathrm{x} 1 \times 2}=\sqrt{\frac{\left(\mathrm{n}_{1}-1\right) \mathrm{S}_{\mathrm{x} 1}^{2}+\left(\mathrm{n}_{2}-1\right) \mathrm{S}_{\mathrm{x} 2}^{2}}{\mathrm{n}_{1}+\mathrm{n}_{2}-2}}$

$\mathrm{x}_{1}$ e $\mathrm{x}_{2}=$ Média das amostras 1 e 2

$\mathrm{S}_{\mathrm{x} 1 \times 2}=$ Desvio padrão amostral

$\mathrm{n}_{1}$ e $\mathrm{n}_{2}=$ Tamanho das amostras 1 e 2

\subsection{Teste $t$ para médias}

Os preços médios da madeira para celulose dentro e fora da região de atuação da Klabin foram, respectivamente, de $\mathrm{R} \$ 59,12$ e $\mathrm{R} \$ 47,70$. O teste $t$ indicou que o preço médio da madeira para celulose dentro da região de influência da Klabin é estatisticamente superior ao fora em nível de significância de 5\% (Tabela 3).

Tabela 3 - Resultados do teste $t$ para o comparativo dentro e fora da região de atuação da Klabin para os preços da madeira para celulose e processamento mecânico.

Tabela 3 - Results of $t$ test for comparison within and outside of Klabin's operation area for pulpwood and sawnwood prices.

\begin{tabular}{lcccc}
\hline & $t$ & $\mathrm{gl}$ & $\begin{array}{c}\text { Sig. } \\
\text { (bicaudal) }\end{array}$ & $\begin{array}{c}\text { Diferença entre } \\
\text { as médias }\end{array}$ \\
\hline PC & 3,21 & 81 & 0,002 & 11,42 \\
PPM & 0,17 & 347 & 0,87 & 0,69 \\
\hline
\end{tabular}

Quanto ao preço do processamento mecânico, não foi detectada diferença estatisticamente significativa entre os preços nas regiões analisadas a 5\% de significância. Os preços dentro e fora da região foram praticamente os mesmos, e as médias encontradas foram de $\mathrm{R} \$ 76,47$ e $\mathrm{R} \$$ 75,78 , respectivamente (Tabela 3 ).

Os resultados da Tabela 3 não foram conforme o esperado, ou seja, a região de atuação da Klabin não pratica um preço para celulose inferior ao do mercado paranaense, e sim o inverso, e o preço para o processamento mecânico dentro da região não é superior ao registrado fora desta. Guardadas as devidas limitações, essas evidências sugerem que a Klabin não utiliza seu poder de mercado na formação do preço da madeira em sua região.

As principais limitações do trabalho referem-se à definição do tamanho da área de atuação da Klabin e à consideração de custos de produção e produtos semelhantes em todo o Estado do Paraná. Certamente, qualquer definição sobre a área de atuação da Klabin será passível de crítica, pois esta é variável conforme as necessidades e estratégias da empresa e, sabiamente, é esperado que grandes empresas possuam economias de escala, melhores clones e custos de produção menores, bem como melhores tratos silviculturais e uma madeira diferenciada e mais valiosa para o processamento mecânico. Entende-se que as limitações são diluídas pelo fato de se trabalhar com médias de um grande número de municípios e que, apesar das limitações e se analisados com cautela, os resultados contribuem para o entendimento da formação do preço da madeira na região.

\section{DISCUSSÃO}

Apesar do evidente poder de mercado da Klabin, o qual, teoricamente, sugere que a empresa influencia a formação do preço da madeira na busca de uma maximização de lucro na sua comercialização, isso pode não acontecer, pois uma busca pela maximização de lucro na atividade florestal pode entrar em conflito com a maximização de lucro na produção de papel e celulose foco principal da empresa. Provavelmente, pode ser muito mais importante garantir um mercado florestal ativo e eficiente, de forma que a empresa não corra nenhum risco de falta de madeira para a expansão de sua produção de papel em longo prazo.

Assim, um maior lucro na venda de madeira mais grossa ou a compra de madeira fina por um preço inferior ao que ocorreria em uma estrutura de concorrência pode não ser interessante. Um preço injusto da madeira fina

Cerne, Lavras, v. 18, n. 1, p. 153-158, jan./mar. 2012 
poderia afugentar pequenos produtores da atividade florestal e direcioná-los para a agricultura ou pecuária; já um preço desproporcional da madeira mais grossa poderia direcionar esses mesmos produtores a manejar sua floresta para concorrer com a empresa na oferta de madeira para as madeireiras. Dessa forma, em ambos os casos, haveria redução na disponibilidade de madeira para a empresa. Portanto, deve-se considerar, na base teórica, a concorrência no pólo.

A indústria de papel e celulose é de capital intensivo, possui custos fixos elevados e uma capacidade ociosa extremamente custosa (FISCHER; WAQUIL, 2009), fatores estes que reforçam a preocupação com a sustentabilidade de madeira em lugar do lucro no comércio desta. Tendo em vista a complexidade do planejamento florestal em função do longo prazo de maturação das florestas, o que implica a árdua tarefa de prever a demanda de produtos de madeira em um período extremamente longo, provavelmente, a cautela deve permear as decisões referentes ao abastecimento de madeira em longo prazo da grande empresa florestal.

Outro fator motivador para as grandes empresas pagarem um preço justo pela madeira e buscarem atrair pequenos produtores para a atividade florestal, além de ser uma política positiva para a imagem da empresa, é a possibilidade de reduzirem o seu custo na aquisição de novas áreas e, indiretamente, aproveitarem de algumas benesses governamentais direcionadas a pequenos produtores. O PRONAF Florestal - linha de crédito disponível apenas a pequenos produtores - cobra juros de até $1 \%$ a.a., bem inferior a alternativas de crédito disponíveis para empresas como, por exemplo, o PROPFLORA que prevê juros de $8,75 \%$ a.a. O código florestal também trata pequenos produtores de forma diferenciada em alguns aspectos, como, por exemplo, no cômputo da área para reserva legal.

Um indicativo de que a estratégia das grandes empresas vem sendo a busca de pulverizar a atividade florestal e, teoricamente, reduzir o seu poder de mercado é o crescimento do fomento e arrendamento florestal. Segundo dados da Associação Brasileira de Produtores de Florestas Plantadas - ABRAF (2010), enquanto o fomento e arrendamento florestal paranaense cresceram $69 \%$ e $71 \%$ entre 2005 e 2008, a área de plantios próprios caiu 3\% no mesmo período. Em 2008, a área de fomento e arrendamento somou mais de 90 mil hectares, o que já representa quase $40 \%$ da área total de florestas plantadas do Estado do Paraná.

\section{CONCLUSÕES}

A análise dos resultados do trabalho permitiu as seguintes conclusões:

- A madeira para celulose é mais valorizada dentro da região de atuação da Klabin, comparativamente ao restante do Estado, tornando-se uma vantagem para os pequenos produtores de madeira localizados na proximidade da empresa.

- As empresas do processamento mecânico dependentes da madeira proveniente da região da Klabin não pagam um preço superior ao praticado no Estado. Considerando apenas o preço da madeira, é indiferente para uma madeireira localizar-se dentro ou fora da região de atuação da Klabin.

- Não é possível afirmar que a Klabin utilizou o seu poder de mercado na busca de aumentar seu lucro na compra ou venda de madeira em 2008, podendo ser encontrados resultados diferentes para outros anos, desde que modificada a estratégia da empresa.

\section{REFERÊNCIAS}

ALMEIDA, A. N. Estudo econométrico da demanda e oferta de madeira em tora para o processamento mecânico no Estado do Paraná. 2006. 217 f. Dissertação (Mestrado em Ciências Florestais) - Universidade Federal do Paraná, Curitiba, 2006.

ASSOCIAÇÃO BRASILEIRA DE PRODUTORES DE FLORESTAS PLANTADAS. Anuário estatístico da

ABRAF. Disponível em: <http://www.abraflor.org.br/ estatisticas.asp>. Acesso em: 3 abr. 2010.

FISCHER, B. B.; WAQUIL, P. D. Sistemas de certificação florestal no setor brasileiro de papel e celulose: influências no desempenho exportador. Revista de Economia Agrícola, São Paulo, v. 56, n. 2, p. 5-19, 2009.

GRAÇA, L. R.; RODIGHERI, H. R.; CONTO, A. J. Custos florestais de produção: conceituação e aplicação. Colombo: Embrapa Florestas, 2000. 32 p. (Documentos, $50)$.

INSTITUTO BRASILEIRO DE GEOGRAFIA E ESTATÍSTICA. Banco de dados do SIDRA. Disponível em: <http://www.sidra.ibge.gov.br>. Acesso em: 4 abr. 2010 .

Cerne, Lavras, v. 18, n. 1, p. 153-158, jan./mar. 2012 
LEITE, A. L. S.; SANTANA, E. A. Índices de concentração na indústria de papel e celulose. Disponível em: $<$ http:// www.abepro.org.br/biblioteca/ENEGEP1998_ART158.pdf>. Acesso em: 3 abr. 2010.

NOCE, R.; CARVALHO, R. M. M. A.; CANTO, J. L.; SILVA, M. L.; MENDES, L. M. Medida da desigualdade do mercado internacional de compensado. Cerne, Lavras, v. 13, n. 1, p. 107-110, jan./mar. 2007.

PESTANA, M. H.; CAGEIRO, J. N. Análise de dados para ciências sociais: a complementaridade do SPSS. 4. ed. Lisboa: Silabo, 2005. 690 p.

SANTOS, M. A. S.; SANTANA, A. C. Concentração e poder de mercado das empresas de artefatos de madeira do Estado do Pará. In: ENCONTRO NACIONAL DE ENGENHARIA
DE PRODUÇÃO, 23., 2003, Ouro Preto. Anais... Ouro Preto: UFOP, 2003. Disponível em: <http://www. bancoamazonia.com.br/.../Concentracao_poderdeMercado empresasdeartefatosdemadeiradoPara.pdf $>$. Acesso em: 3 abr. 2010 .

SOARES, T. S.; NISHI, M. H.; OLIVEIRA, P. R. S.; SILVA, M. L. Concentração no consumo de madeira e estrutura de mercado do setor moveleiro do município de Ubá/MG. Revista Científica Eletrônica de Engenharia Florestal, Garça, ano 4, n. 7, fev. 2006. Disponível em: < http://www. revista.inf.br/florestal07/pages/resenhas/nota03.pdf $>$. Acesso em: 3 abr. 2010 .

SOUZA, N. A. Arranjos produtivos locais: o caso de chapas e laminados de Ponta Grossa. 2005. 142 f. Dissertação (Mestrado em Desenvolvimento Econômico) - Universidade Federal do Paraná, Curitiba, 2005.

Cerne, Lavras, v. 18, n. 1, p. 153-158, jan./mar. 2012 